European journal of American studies

\title{
Stanley Park, Literary Ecology, and the Making of Sustainability
}

\section{Georg Drennig}

\section{(2) OpenEdition \\ Journals}

Electronic version

URL: https://journals.openedition.org/ejas/11382

DOI: 10.4000/ejas. 11382

ISSN: 1991-9336

Publisher

European Association for American Studies

\section{Electronic reference}

Georg Drennig, "Stanley Park, Literary Ecology, and the Making of Sustainability", European journal of American studies [Online], 10-3 | 2015, document 2.7, Online since 31 December 2015, connection on 08 July 2021. URL: http://journals.openedition.org/ejas/11382 ; DOI: https://doi.org/10.4000/ejas. 11382

This text was automatically generated on 8 July 2021.

Creative Commons License 


\title{
Stanley Park, Literary Ecology, and the Making of Sustainability
}

\author{
Georg Drennig
}

\section{Introduction}

The study of urban systems and the role of cities in debates about sustainability is a fashionable topic in numerous fields in academia, with the need for interdisciplinary research being a much-voiced aspect of such academic interest. Yet the contributions of the humanities and the study of culture to these debates stay within the respective disciplines of studying literature and popular culture. In the following reading of Timothy Taylor's 2001 novel Stanley Park, I intend to explore an avenue that offers some way of making literary studies relevant to the discussion of sustainable cities and the future of urbanity. Following a brief discussion of the possible contributions of literary studies to a better understanding of urban sustainability, the specific ways in which literature can do cultural work within the social setting of the city shall be investigated. Hubert Zapf's triadic model of the novel's function in a cultural ecology-fully developed in his 2002 book Literatur als kulturelle Ökologie-will be discussed and brought to bear on Taylor's 2001 Vancouver novel Stanley Park. This reading will investigate Taylor's engagement with questions of urban sustainability, and then briefly explore the question of how such a book can play a role in fostering urban sustainability.

\section{Literary Studies and Questions of Urbanity}

The current academic debate about cities, the ways to study them and to make the insights gained thusly useful for practitioners seems mostly to take place among the hard sciences, fields related to engineering and urban planning, and sociologically inclined disciplines. Cultural phenomena such as street art, especially, are acknowledged, yet dealt with as symptomatic of other phenomena such as 
gentrification, and thus in turn not approached from an angle that cultural and literary studies would explicitly be called to contribute to. A similar dynamic applies in the case of studying urban complexity, which has become increasingly prominent in recent years; the fact that otherwise hard-to-obtain insights could indeed be added to the field by calling upon the humanities to contribute has so far been barely recognized, though literary scholars are beginning to explore urban complexity from their perspective. ${ }^{1}$ Indeed, the challenge of fostering a transdisciplinary dialogue that goes further than simply acknowledging or adapting the insights of different fields-the reframing of concepts from life-sciences in literary ecocriticism comes to mind-has been recognized, and steps have been taken in the humanities to address the lack of approaches that put the needs of the object of study before disciplinary constraints. ${ }^{2}$

Still, the humanities have not yet produced a coherent set of methods that are explicitly geared towards making a contribution to the debate about urban sustainability in the $21^{\text {st }}$ century and beyond, nor are other disciplines yet sufficiently aware of what additional-and needed-understanding literary and cultural studies could add. As Hubert Zapf argues, "literary culture ... probably has a special potential for the reintegration of different areas of cultural knowledge that are kept separate in other forms of discourse" ("Literary Ecology" 850). In her dissertation, Maia Joseph writes in a statement more specifically concerned with understanding urbanity, that:

Literary texts are...the carriers of a certain kind of knowledge-subjective, experimental, affective, interactive, often reflexive; this is knowledge that many planning scholars and practitioners value, but that can be difficult to articulate and integrate into planning and development discourse. (6)

Indeed, the humanities and especially ecocriticism have the tools to excavate said knowledge; though the ways and means to make this knowledge useful to others seem to be missing, there are clear contributions that have been made and have a theoretical and methodical foundation.

The best recognized and most-often stated contribution that literature and its study make to understanding urbanity is through the role of the writer as a cultural diagnostic. As Jens Gurr and others have argued, ${ }^{3}$ quantitative approaches to questions about the city cannot account for their affective, sensual dimension. Literature of and about the city can transcend the technological language of planning discourse as well as draw attention to issues and questions that, as they are not quantifiable, evade the grasp of statistical analysis. Zapf's statement that "the narrative mode is necessary to provide a medium for the concrete exemplification of ethical issues that cannot adequately be explored on a merely systematic-theoretical level" ("Literary Ecology" 853) can thus be adapted to urban studies. Urban systems theory and the disciplines that draw upon it are inherently unable to explicate or make insights available to the much more amorphous mode of literary representation and its study. Neil Evernden's proposition that " $[\mathrm{t}]$ he artist makes the world personal-known, loved, feared, or whatever, but not neutral... . Perhaps it is a cultural simulation of a sense of place" (100), therefore points to the specific and unique role that culture can take in the urban debate. It can serve as an arena of exploration, diagnosis, and speculation, and in the process, make knowledge accessible that would otherwise be missing from the study of urbanity.

This becomes somewhat ironically evident in the study of complex urban systems, which is, at first sight, clearly a matter for hard sciences and mathematical 
modeling. Several salient features of urban complexity that also make it subject of mathematical interest and quantitative study-such as emergence, nonlinearity, heterogeneity and hybridity ${ }^{4}$-are not only also of interest to the study of culture: complexity in its non-linearity can be made understandable through "nonlinear forms of knowledge" (Zapf "State" 53, cf. Zapf Literatur 50). Those are precisely what literature excels at producing and representing, and what literary studies-as Zapf argues, especially in their ecocritical inflection-are well-equipped to investigate.

Though the relationship of the study of culture to investigations into urban complexity and methodologies are still in the making, more general theories about cultural imaginaries are easily adaptable to the question of what literature actually effects within urban culture. Drawing upon Wolfgang Iser and Winfried Fluck's work on cultural imaginaries, Zapf, in his theoretical work on literary ecology, conceives of culture as an ecological system, in which literature then acts as a life force that brings renewal and regeneration to a system that would otherwise be moribund. He allows a special role for fiction, or imaginative literature, and considers it "an ecological principle or an ecological energy within the larger system of cultural discourses" ("State" 55). In their turn, Jens Gurr and Martin Butler apply this general idea of culture as an ecological system to cities, and read cultural work-including imaginative literature but not limited to it-as force fields that shape the way readers and audiences perceive, and thus participate in the shaping of their own urban environment (cf. 85-85). Culture, from this point of view, can become a factor in shaping the ideas of urban agents about what places their cities are, and more importantly, what they could be. While this essay views the concept of culture as a "life force" skeptically and to be approached with caution lest urban practitioners can too easily dismiss literary studies approaches as overly esoteric, the following considerations do take seriously the notion of literature's power to motivate, inspire, and inform the actions of city dwellers and decision makers.

The following considerations will neither provide clear instructions on how to apply literary insights to urban planning, nor will they exhaustively explore possible methodological approaches to better doing so. Reading the novel Stanley Park through the lens of Zapf's triadic model of the function of literature in cultural ecological systems, however, sheds light on the ways fiction can negotiate cultural diagnosis with the imaginative potential closed to non-fictive ways of writing. This model of literature as a cultural intervention that offers critical cultural diagnosis, stages the repressed, and suggests ways of bringing seemingly opposite discourses together, makes sense in both a rather close reading of the novel and when putting the work into the larger context of urban change in Vancouver. Hopefully, this may provide an example of how a novel makes sense of urban issues on its own terms, and indeed can be a factor in shaping the understanding that city dwellers have of their own environment. Stanley Park indeed offers ideas of sustainability that continue to resonate in Vancouver's spatial practice. While it did not necessarily cause such things into being-after all, this article argues that writers engage in diagnostics-it did bring ideas to a larger public awareness, also due to the fact that the novel did gain some local prominence after its publication. 


\section{A Triadic Reading of Stanley Park}

In the triadic model of Hubert Zapf, there are three functions imaginative literature can fulfill in the larger cultural ecosystem ${ }^{5}$ : novels can do the work of providing a critical metadiscourse, offer an imaginative counterdiscourse, and, through a re-integrative interdiscourse, effect a reconciliation of seeming opposites, and transcend the binary of meta- and counterdiscourse. In the critical metadiscourse, literature makes the aforementioned cultural diagnosis and larger social critique by representing systemic deficits, injustices, and the way hegemony destroys cultural vitality. By staging the culture's repressed elements, literature then offers a different model of social relations and practices in the mode of an imaginative counterdiscourse or a plural of those, which-and in his considerations, Zapf somewhat overburdens the idea of a cultural life force-derives special power from aesthetic effects unique to literature. In a re-integrative interdiscourse, novels can then attempt to reconcile their critique of cultural reality with their own imagination and, through images of revitalization, bring culturally separate phenomena and discourses together.

Im Stanley Park, this discursive triad works in two different ways. In the story of the protagonist Jeremy Papier's failure as an independent restaurateur bought up by an international business mogul, his subsequent experiences cooking for, and learning from, the homeless of Vancouver's Stanley Park, and his grand gesture of secretly bringing foraged foodstuffs to an elite audience in the restaurant he is forced to work for, all of Zapf's modes are represented. A first reading of the novel will therefore be primarily interested in the themes of rootlessness and alienation, artfulness and craft as opposing forces, and chef Jeremy's final prank as a re-integrative interdiscourse. On a somewhat different level, however, the plot's movement in and out of different social, economic, and culinary spaces of Vancouver negotiates a triad that directly addresses its urban setting. The urban change, collective memory, and guerrilla placemaking that the second reading of the novel's triadic structure will investigate can be understood to resonate with the themes addressed previously. It is then on this contextualized plane on which the novel can be read as a piece of engaged and interventionist writing that may yield insights about, and suggest ways of improving urban sustainability, and provide something of an antidote against an alienated and placeless mode of urbanity.

1 It is this issue of placelessness and alienation that Stanley Park's critical metadiscourse attacks through the voice of its protagonist and his approach to cooking. Chef Jeremy Papier, distinguishes between two culinary modes, the names of which are borrowed from gang culture: Blood, which is a traditional cuisine of place, and the globalized postnational Crip approach, which from Jeremy's perspective, is placeless, ignorant, and incoherent. This notion is extended to the provenance of ingredientsand here the issue of sustainability already becomes relevant-as in the case of Jeremy's aversion against farmed salmon:

The fish in such a pen lived independent of geography, food chain, or ecosystem.

These salmon were perfectly commodified as a result, immune to the restrictions of

place. There was no where that these fish were from. (171)

1Yet his creditor, Dante Beale, is the owner of the deeply placeless Inferno Coffee chain, and as Jeremy's restaurant The Monkey's Paw fails, his only option for fiscal survival is to become chef of the deeply Crip restaurant Gerriamo's, in which Beale's successful approach is one of a cuisine ignorant and uncaring of its location or any 
tradition. Jeremy's moral indictment of this-economically more successful-way of dealing with food shines through in a sarcastic statement he gives to a food journalist about Gerriamo's culinary vision: “This is not fusion. We are the restaurant of no place. We belong to no soil ... to no culinary morality. We only belong to those who can reach us and understand us and afford us" (364).

Set against this critique of culinary business culture, and by extension, society, which is ignorant of place and roots, are Jeremy's restaurant The Monkey's Paw and his notion of Blood cuisine, as well as the anthropological work of his father in Stanley Park. For chef Jeremy, "Blood Cooks were respectful of tradition ... interested in the veracity of things culinary, ... linked to a particular manner and place of being" (33). The Monkey's Paw is thus conceived as a "restaurant other chefs would go to. Local but not dogmatic. It wasn't a question of being opposed to imported ingredients, but of preference, of allegiance, of knowing what goodness came from the earth around you" (51). Jeremy's father, in the novel referred to as the Professor, echoes his son's concerns. An anthropologist working on, and in what he calls a participatory approach, living with the homeless people sheltering in the park, the Professor articulates concerns similar to his son. He constantly draws attention to how his son's culinary allegiance and application of rooted skill and his own work of studying the craft of sheltering in the park are both "about how people relate to the land on which they stand" (136).

These two positions then meet in the novel's imaginative counterdiscourse when Jeremy becomes jobless after his business fails and he begins to cook for the homeless of the park in impromptu potluck dinners. There, the skill of the homeless urban hunter and forager represented by the character Caruzo, meets the chef's French training, leading to the communion of eaters and the transformation of ingredients considered abject by most of urban society:

As had become their practice, they snared squirrels for dinner, two reds and a grey, and Jeremy roasted them, spread-eagling the gutted carcasses on Caruzo's grill [improvised from an upturned shopping cart]. He sent Caruzo off to gather huckleberries and dandelion greens and combined these with roasted potatoes ... . Nobody observed that the squirrels, with their sinewy flesh spread unevenly over bony carcasses, had been perfectly roasted. That the beer marinade he'd applied during cooking had caramelized into a mahogany brown. (249)

What results from Jeremy's proverbial time in the wilderness is an even stronger appreciation of the essential function of food and the way it can provide a sense of community. Yet the skill of all three, the chef, the professor, and the homeless, and the potluck dinners that are repeatedly described in the novel, are still relegated to the economic and spatial margins of urban society. It is then in the mode of a re-integrative interdiscourse that Taylor constructs the novel's climax, in which Jeremy takes the lessons learned in the park and brings them to an elite audience of gourmets and successful entrepreneurs.

As part of the deal that saves Jeremy from financial ruin but also spells the end of The Monkey's Paw, Dante Beale employs Jeremy as the chef of his own restaurant venture Gerriamo's. It is in Jeremy's performance on opening night that the novel then provides an unexpected image of vitality that works against the placelessness of Dante Beale's market-researched mode of doing business. Though the menu of Gerriamo's opening night is deeply Crip-exotic but unrelated international ingredients brought together in an affected display of creativity-Jeremy secretly sources many of the 
foodstuffs from Stanley Park. Thus, the foraging and hunting skills of the homeless provide the basis for a deeply rooted and local mode of cooking.

There was a bucket of dandelion greens and fiddleheads, as well as a garbage bag full of salal, salmon and huckleberries. A dozen plump Canada geese, a dozen grey rock doves, six canvasbacks, four large rabbits, sixteen squirrels (greys, fatter and more plentiful than reds) four huge raccoons and a swan. (355-356)

It is through this dinner-though the guests are unaware of the nature of the ingredients, as they are camouflaged by the fake names of items on the menu-that Jeremy makes his grand statement, providing in his view "messages about knowing the earth's bounty ... where one stood, understanding the loyalty and sanctity of certain soil" (389). In spite of this performance being half-hidden, Jeremy is convinced that he has provided the kind of vital impulse or "life force" that Zapf's triad conceives of as coming from the re-integrative interdiscourse (cf. Joseph 226):

[T] he celebrants, he found himself thinking ... had been fed. Fed well. Fed goodness like they never had been fed. And they had eaten it, been delighted, were now satisfied and strengthened and full of unknowable joy. Sanctified by his efforts. It was possible ... to briefly feel messianic. Like he had done a truly great and lasting thing. (402)

In this sense, Stanley Park's climactic dinner literally infuses a "life force" into a subculture-Vancouver's gourmet and business elite-that has become moribund and alienated.

Taylor, however, inserts into his novel a critical awareness of the fleeting nature of such an action, and repeatedly questions both Jeremy's Blood allegiance and Dante Beale's construction as unfeeling and even infernal capitalist. Not only does Jeremy fail as an entrepreneur and commits fraud in the process-which Taylor is probably more critical of than most of his readership ${ }^{6}$-but the problematic nature of his ideology of Blood cooking is several times hinted at. His co-chef Jules Capelli's comment that he is something of "the Pacific Northwest's pre-eminent Food Nazi" (181) can be read as humorous, yet it does draw attention to the way it echoes, (especially German) discourses of blood and soil, which eventually became a pillar of European fascist ideology. On a more explicit and less academic level, the novel's scenes at a festival dedicated to local food point to the privileged aspect of Blood cuisine that is primarily consumed by affluent gourmets (262), Stanley Park's imaginative counterdiscourse of practices in urban parklands notwithstanding. The book's critical metadiscourse is also, to a degree, subjected to questioning. Though Dante Beale is repeatedly and explicitly imbued with infernal attributes-Jules' and Dante's dislike of each other is compared to that of "Gabriel and Belzebub" (65)-even Jeremy's godson jokes about the overly simplistic view implied by this playing with names and symbols (cf. Mason $\mathrm{ft} 8^{7}$ ).

in contrast to the way Stanley Park often ironically deconstructs its own ideological dichotomies or draws attention to their shortcomings, its spatial discourses leave less room for ambiguity. In the context of the novel's Vancouver, the triad of cultural criticism, stage for the repressed, and reconciliation and rejuvenation provide literary space for a more trenchant critique. Dante's Inferno Coffee becomes a homogenizing agent that reshapes the cityscape, while Stanley Park and The Monkey's Paw offer only precarious spatial alternatives, though the park becomes the site of the book's intervention in the urban memory. The space of re-integration, Jeremy's final project Food Caboose, then, though firmly in the mode of guerrilla placemaking, offers 
only a degree of escape from the Post-Fordist urban restructuring that has so prominently shaped Vancouver over the last few decades.

in the novel's critical metadiscourse, Inferno Coffee-an obvious sibling to the Starbucks Coffee chain-becomes a force of homogenization and de-localization, actively erasing spaces that are different. The novel uses, for example, Jules' views to make this homogenizing effect explicit. In her opinion, "Inferno was polluting the city with sameness. Inferno was a cost model, an exercise in scale. Inferno was a celebration of everything they [The Monkey's Paw] were not" (66). While The Monkey's Paw is host to a display of urban diversity, a "multicultural client base that nobody could consciously target" (52), Dante's business model relies on clearly structured neighborhoods that offer a base of:

consumer types to whom Dante felt confident he could sell, always sell, reliably sell every morning and lunch, to the extent that there was a business case for the investment in blond wood, canned music, and barista training. (63)

Yet urban change works against the diversity of The Monkey's Paw and replaces it with Gerriamo's, just as the restaurant's neighborhood changes in a brutal mirroring of the reality of the Vancouver neighborhood that the novel uses as a setting. Thus, Inferno Coffee gains a foothold "around the corner in the space that had been Fabrek's falafel stand" (294). Such displacements are not limited to the diverse neighborhood of Crosstown, but noted by Jeremy even in the affluent West End on the border to Stanley Park, where he remembers an "aging co-op resident" who had kept "a nail-hold on the land that held so much of her" (110) against a major developer restructuring the urban space.

If this instance of remembering urban change and displacement is a familiar story, the space of Stanley Park's imaginative counterdiscourse stages a much more strongly repressed element. During one of his nightly visits to the park, Jeremy observes a First Nations family that dwell there. As his father explains in full professorial mode:

These people are taking a last stand. Homing in on a place that cannot be taken from them. You see, their language belongs to this land...the land itself cannot be taken.... It can't be expropriated, built up, paved over, strata-titled. These speakers of an ancient tongue, their actions are the sociolinguistic equivalent of taking sanctuary in a church. (135)

The problematic equation of naturalness with aboriginal peoples that Taylor constructs in these few scenes notwithstanding, the novel here does important cultural work. It reminds readers of a historical First Nations presence which had been erased both physically and from the memory of Vancouverites (cf. Barman). Though the book's potential romanticization of homelessness can also be seen as problematic, it does link skill to the urban fabric, and raises the issue of knowledge and individual usage of space. Jeremy himself undergoes a process from helplessly stumbling through the park at night to where a visit "felt like coming home .... Jeremy walked the trails with certainty, knowing exactly where he was relative to his destination" (346). As the Professor claims, this way of skillfully navigating the urban territory is at least marginally a means of claiming ownership of urban space otherwise subject to a regime of real estate interest, or at least fighting alienation and a sense of placelessness: "A farmer touches the earth in his fields. He thinks, this land is mine. A person in the city, too, they walk their favorite streets, they visit their favorite parks" (117). ${ }^{8}$ 
Erom the point of view of a spatialized reading, Stanley Park's re-integrative interdiscourse does not reconcile these concerns of memory and resistance to capitaldriven urban change with the dominant order. Jeremy's final restaurant project that follows his work at Gerriamo's, the Food Caboose, however, does use a space forgotten or ignored by the real estate industry, and at least allows his work as an independent restaurateur to continue. Located on the southern fringes of Chinatown, the Food Caboose is an unregistered establishment that needs an otherwise marginal space to remain undetected by authorities. Taylor lays out this setting as follows:

In more recent years the colorful community of vegetable stalls and butchers, spice vendors and the sellers of ancient cures had contracted into a few square blocks around Main Street to the northeast. The beachhead of condo development to the southwest had stalled in its advance this direction. Buildings had been torn down and not replaced. The area stopped being part of any neighborhood at all. (419)

The guerrilla restaurant that allows Jeremy to pursue his culinary vision outside of the system depends on an unstable spatial setup that is under constant threat by possible changes in the real estate market. How precarious this position is, also becomes clear by Taylor's use of words from a military register such as "advance" and "beachhead" of development. If the Food Caboose can be read as a space of reintegrative interdiscourse, then it is a highly unstable one. Also, in a twist that reveals the compromise at work when imaginative counter discourse meets "reality," it is subject to mechanics of social and spatial exclusion. As Maia Joseph states in her reading of Stanley Park:

Jeremy seems to have trouble bringing his new understanding of urban community out of what we might describe as the dream-space of Taylor's Stanley Park and applying it to his work as restaurateur. (250)

Gaining entrance to the Food Caboose is radically different from the relative openness and diversity that marked The Monkey's Paw. Instead, guests have to be referred by already established list members, and then undergo a highly complicated reservation process in order to eat there. Chef Jeremy may have, through this appeal to secrecy and exclusiveness, and through escaping the vagaries of the real estate market, established a financially viable enterprise that allows him and Jules Capelli to keep going with their project of serving local bounty; it does, however, come at the cost of social exclusion and the acknowledgment of a capitalist logic, and therefore shows the limitations of bringing the experience of communion through place-aware food to "celebrants" on a regular basis.

Nevertheless, Stanley Park provides both critical cultural diagnosis and makes a clear argument for ways to live differently in the city. Its critical metadiscourse links urban change fueled by a logic of capital investment to both literal and metaphorical displacement, and to a culture that becomes homogenized and amnesiac at the same time. Jeremy's place-aware restaurant project becomes removed-or displaced-by the logic of capital that cannot be concerned with the intricacies of art and skill of being in place, exactly those things that Blood cuisine and the Professor's studies represent. In the space of imaginative counterdiscourse, Taylor's novel then stages numerous tactics that apply knowledge and rootedness to the urban fabric. Obtaining something as essential as one's sustenance from urban surroundings, ${ }^{9}$ celebrating community through food, learning to make one's way and actively map one's surroundings, or even simply remembering the indigenous presence in the park are all acts that allow Jeremy and the other characters to engage with their urban setting differently. These acts may 
be fleeting, and by their nature be marginal, but the novel articulates them as worthy endeavors nevertheless, that may help contribute to a larger cultural awareness which in turn may change the larger material urban fabric after all.

\section{Ways Towards a Conclusion}

Though a basic argument about how a novel such as Stanley Park can play a role in making cities more sustainable can be easily made-and the novel itself does so-, this article intends to build on Zapf's argument about the special resources available to imaginative literature. This leaves the more problematic question of how the study of literature itself can play a role in such a process. The following considerations will first look at the specific reception of Stanley Park, then turn once more to the question of a "life force" in culture, and then briefly remark on the role of aesthetics and specific modes of representation only available to fictive writing. None of this yields a blueprint for how to engage urban practitioners and scholars from outside the humanities, though some final remarks will hopefully indicate starting points for this necessary process.

The city that provides the setting for the novel, and arguably features as a character itself, reacted positively to the book. In 2003, it was featured by the Vancouver Public Library's citywide reading initiative, it was nominated for the Giller Prize, and in the experience and analysis of local scholar and expert Maia Joseph centrally "contributed to the 'shaping' of the conversation about local culture and community" (221). It thus clearly made its critique and ideas enter a larger urban conversation, a notion mirrored in the novel itself: Jules Capelli claims that one of the functions of The Monkey's Paw in the Vancouver culinary scene is to fuel people's imaginations, so that "in the great, culinary meme-pool, their ideas were now loose" (210). The placemaking tactics suggested in the novel's imaginative counterdiscourse absolutely resonate with what can be called the "meme-pool" of alternative and arguably sustainable methods of gathering food in cities-from urban foraging and harvesting over guerrilla gardening to freeganning and the practice of locavore-ismthat were even featured as part of the Vancouver Art Gallery's We: Vancouver exhibition on the occasion of the city's 125th anniversary (cf. Drennig).

The "meme-pool" of Jules Capelli is in the context of this paper a different way of referring to the cultural imaginary or what Zapf calls the cultural ecology. The notion that the cultural articulation of ideas can make certain ways of doing things thinkable and thus possible as they become part of a widely shared imaginary (cf. Zapf Literatur 59, Fluck 20-21, Charles Taylor 24-28) is central to literature's potential in fostering sustainability. What Zapf frames as the vital force in a cultural ecology is then, colloquially framed, the injection of new ideas into the larger pool of things considered possible and feasible within a culture. As has been shown above, Stanley Park clearly provided such an injection or bolstering of ideas into Vancouver's public conversation about itself and the practices possible in the city. Even though this article has announced a degree of skepticism about the "life-force" metaphor for literature's role in the public conversation that is culture, it does argue that literature may play a special role in such processes.

What literature has to offer in comparison to other modes of cultural articulation-which, in their turn, have distinct advantages of their own, as street art 
clearly demonstrates (cf. Gurr and Butler)-is the way it can handle allusion and different perspectives and voices. Zapf indeed argues that an understanding of fictive literature as a "life force" needs to account for literary aesthetics and their impact (Literatur 5, 46). In Stanley Park, Taylor makes use of different voices that allow for varied articulations of similar themes, potentially broadening their appeal to readers. The imaginative counterdiscourse therefore becomes something to be thought of in the plural, as the Professor, Jeremy, and numerous other characters have different takes on what exactly constitutes their alternative practices and the meanings and motivations behind them, whether that is Jeremy's allegiance to Blood cuisine, Jules' strong dislike of corporate homogenization, or the Professor's search for a deeper understanding of rootedness in the late-capitalist metropolis. In contrast to other forms of cultural critique and articulation of alternatives, the multiple narrative voices available to literature allow a larger variety of affective responses and create a playing field for ideas within one work. Though leaving more space for ambiguity in the criticisms voiced by a number of voices instead of one narrator, and though in this case making the characters' ways of engaging with their urban setting mutually exclusive, this multi-faceted approach is more open to its audience's uses and adaptations; staying in the metaphor of the cultural ecology, this would then mean that the "life-force" unique to literature can foster a unique and broad biodiversity of ideas and practices of sustainability.

Yet, as this article has argued at its outset, it is not enough for the literary studies scholar to point at the value of books in creating a culture of urban sustainability. One step is to direct our attention to works, such as Stanley Park, which themselves are explicitly or implicitly dealing with practices of sustainability and can provide an urban ecocritical pedagogy that is not too overtly didactic or bound up in generic constraints (cf. Gersdorf 38). Especially if, as is the case in Taylor's novel, these novels do not fall into any current research paradigm. ${ }^{10}$ Our analyses then need to be accessible beyond the bounds of our disciplines. Whether Zapf's ${ }^{11}$ concept of cultural ecology may have appeal outside of the humanities because of its accessibility, or reinforce an image of unscientific and evasive thinking, it is worth considering how our models and interpretive lenses may allow us to enter our voices into the debate. Finally, and admittedly on an unrelated note, it is important that we, scholars of the humanities, acquire a better understanding of how other fields investigate the city, create their understandings of it, and arrive at the questions they ask. Urban sustainability is a concern that will stay with the academia for a while. The humanities have a contribution to make; for this to be sufficiently heard, however, there is still work ahead.

\section{BIBLIOGRAPHY}

11. Barman, Jean. "Erasing Indigenous Indigeneity in Vancouver." BC Studies 155 (Autumn 2007): 3-30. 
Brandt, Stefan L., Winfried Fluck, and Frank Mehring, eds. Transcultural Spaces: Challenges of Urbanity, Ecology, and the Environment. REAL - Yearbook of Research in English and American Literature 26 (2010).

Davis, Mike. Dead Cities. New York: The New Press, 2002.

De Certeau, Michel. The Practice of Everyday Life. Transl. Steven Rendall. Berkeley, CA: U of California P, 1984.

Drennig, Georg. "Cities of Desire: Ecotopia and the Mainstreet Cascadia Imaginary." Brandt et al. $145-58$.

Evernden, Neil. "Beyond Ecology: Self, Place, and the Pathetic Fallacy." The Ecocriticism Reader: Landmarks in Literary Ecology. Eds. Cheryll Glotfelty and Harold Fromm. Athens, GA: The U of Georgia P, 1996. 92-104

Fluck, Winfried. Das kulturelle Imaginäre: Eine Funktionsgeschichte des amerikanischen Romans 1790-1900. Frankfurt a.M.: Suhrkamp, 1997.

Gersdorf, Catrin. "Nature in the Grid: American Literature, Urbanism, and Ecocriticism." Transcultural Spaces: Challenges of Urbanity, Ecology, and the Environment. Ed. Brandt et al. REAL Yearbook of Research in English and American Literature 26 (2010). 21-40.

Gurr, Jens Martin. “'Urban Complexity’ from a Literary and Cultural Studies Perspective: Key Cultural Dimensions and the Challenges of "Modeling." Understanding Complex Urban Systems: Multidisciplinary Approaches to Modeling. Ed. Christian Walloth, J.M. Gurr, J.A. Schmidt. Heidelberg, New York: Springer International, 2014. 133-150.

Gurr, Jens Martin, and Martin Butler. "On the 'Cultural Dimension of Sustainability' in Urban Systems: Urban Cultures as Ecological 'Force-Fields' in Processes of Sustainable Development.” Generative Process, Patterns, and the Urban Challenge: Fall 2011 International PUARL Conference. Ed. Hajo Neis, G. Brown, J.M. Gurr, J.A. Schmidt. Portland, OR: PUARL P, 2012. 77-86.

Joseph, Maia. “Urban Change and the Literary Imaginary in Vancouver.” Diss. University of British Columbia, 2011.

Mason, Travis. "Placing Ekphrasis: Paintings and Place in Stanley Park." Canadian Literature 194 (Autumn 2007): 12-32.

Rhys-Taylor, Alex. "The Essences of Multiculture: A Sensory Exploration of an Inner-City Street Market." Identities: Global Studies in Culture and Power 20.4 (2013): 393-406.

Steel, Carolyn. Hungry City: How Food Shapes Our Lives. London: Vintage, 2008.

Taylor, Charles. Modern Social Imaginaries. Durham, NC: Duke UP, 2004.

Taylor, Timothy. Stanley Park. Vintage Canada Edition. Toronto: Random House, 2001.

Vancouver Art Gallery. We: Vancouver. Exhibition. Vancouver: 2011.

Zapf, Hubert. Literatur als kulturelle Ökologie: Zur kulturellen Funktion imaginativer Texte and Beispielen des amerikanischen Romans. Tübingen: Niemeyer, 2002.

."The State of Ecocriticism and the Function of Literature as Cultural Ecology." Nature in Literary and Cultural Studies: Transatlantic Conversations on Ecocriticism. Eds. Catrin Gersdorf and Sylvia Mayer. Amsterdam: Rodopi, 2006. 47-69.

."Literary Ecology and the Ethics of Texts." New Literary History 39.4 (Autumn 2008): 847-868. 


\section{NOTES}

1. For a thorough discussion of this problem, see especially Gurr 134-137.

2. See the collection Transcultural Spaces: Challenges of Urbanity, Ecology, and the Environment, for an attempt to provide steps toward this direction.

3. See Gurr's work for a literary studies perspective, or sociologist Rhys-Taylor's essay "The Essences of Multiculture: A Sensory Exploration of an Inner-City Street Market."

4. For a full list of phenomena that characterize complexity and are of interest to scholars from the humanities, see Gurr's contribution in Walloth et al.

5. This is a synthesis of considerations laid out by Hubert Zapf in his book Literatur als kulturelle Ökologie, and the articles on "The State of Ecocriticism" and "Literary Ecology and the Ethics of Texts" respectively, with a focus chosen by me for the purposes of the following argument.

6. As Taylor stated in a personal conversation in Vancouver on May $4^{\text {th }}, 2011$.

7. I am indebted to Glenn Deer at the University of British Columbia, whose class on global foodways in literature (Spring 2011) informed this discussion. In the session concerned with Stanley Park, the novel was compared to a medieval morality play. Indeed, the references to Dante Beale's demonic character are numerous and are made on a variety of levels, as are angelic traits of other characters. Still, I would argue in agreement with Travis Mason that the novel deliberately complicates such a reading and indeed makes fun of it.

8. This suggests a reading of navigational skills as a placemaking tactic in the sense of Michel De Certeau, an avenue this paper cannot explore for reasons of focus and space.

9. Though it is a marginal space, Stanley Park in the novel is not constructed as oppositional to urbanity; the animals that inhabit it and that provide the basis for the potluck dinners in the park and during the grand opening at Gerriamo's are distinctly urban species. See Mike Davis thoughts on the natural history of urban wastelands for a deconstruction of the dichotomy of urbanity and wilderness that can be applied beyond brownfield sites (Davis 361-399). See also Carolyn Steel's Hungry City for how radical-and utopian-the idea of a city feeding itself actually is.

10. Stanley Park does not fall into any "post"-classification of writing; a presentation of this novel at a conference on material culture was coolly received in part because of the book's lack of appeal as either sufficiently artistic or having pop-cultural standing.

\section{INDEX}

Keywords: culinary culture, Hupert Zapf's triadic model, literary ecology, Timothy Taylor, Vancouver

\section{AUTHOR}

\section{GEORG DRENNIG}

University of Duisburg-EssenGeorg Drennig studied North American Studies at the University of Vienna, Austria, and Georgetown University, U.S., and is now a PhD candidate in the Advanced Research in Urban Systems program at the University of Duisburg-Essen. There, he works on 
Environmental Imaginaries of Vancouver and the cultural production of space. His main interests are spatially-turned Cultural Studies, "stone-kicking-realist" Ecocriticism, and discourses of urbanity in popular culture, including comics. He has published essays on topics ranging from Poison Ivy and urbanity in Batman comics and films, Joy Kogawa's Obasan, and Eminem's rejection of Ruin Porn, to Spike Lee's Do the Right Thing and the WTO riots in Seattle. 